\title{
Hubungan Pencapaian Tugas Perkembangan Keluarga Tahap VIII (Aging Family) dengan Perilaku Pemenuhan Kebutuhan Spiritual: Sholat Pada Lansia (The Correlation between Eight Stage (Aging Family) of Family Development Task with the Behavior of Spiritual Fulfillment: Sholat on the Elderly)
}

\author{
Fajar Kharisma, Hanny Rasni, Retno Purwandari \\ Fakultas Keperawatan Universitas Jember \\ JI. Kalimantan No. Kampus Tegal Boto Jember 37 Telp./Fax. (0331) 323450 \\ e-mail: hanny_r.psik@unej.ac.id
}

\begin{abstract}
Not all religious activity in the elderly can be implemented well, so there are limitations due to physical conditions that are not strong anymore. Therefore, the family is expected to motivate and facilitate the elderly to meet the spiritual needs so as to increase devotion elderly against God Almighty. This research aims to analyze the relationship between eight stage (aging family) of family development task with the behavior of spiritual fulfillment: sholat on the elderly in the Sumbersari village, Jember regency. This research was observasional analytic using cross sectional study. Data collection was conducted in December 2017 at 82 elderly by using cluster random sampling. The research result showed that Family development task is reached (56.1\%) and the average behavior of spiritual fulfillment: prayers 69.11. Statistical test used the Spearman rank that indicated $p$-value>alpha with $0.359>0.05$ which meant there was no relation between eight stage (aging family) of family development task with the behavior of spiritual fulfillment: prayers on the elderly in the Sumbersari village, Jember regency. Family support is very important for the elderly, especially in carrying out the task the development of families with elderly. However, the research result obtained family development task not have correlation on the behavior of spiritual fulfillment: sholat in elderly, it can be affected by other factors such as the elderly have confidence and awareness in carrying out religion activities such as sholat for the provision in the after life.
\end{abstract}

Keywords: aging family, sholat, elderly

Abstrak
Pada usia lanjut tidak semua aktivitas keagamaan dapat dilaksanakan dengan baik, sehingga ada keterbatasan yang disebabkan kondisi fisik yang tidak kuat lagi. Oleh karena itu, keluarga diharapkan dapat memotivasi dan memfasilitasi lansia untuk memenuhi kebutuhan spiritual sehingga dapat meningkatkan ketaqwaan lansia terhadap Tuhan Yang Maha Esa. Penelitian ini bertujuan untuk menganalisis hubungan antara pencapaian tugas perkembangan keluarga tahap VIII (aging family) dengan perilaku pemenuha kebutuhan spiritual : sholat pada lansia di Kelurahan Sumbersari Kecamatan Sumbersai Kabupaten Jember. Desain penelitian yang digunakan dalam penelitian ini adalah penelitian korelasi dengan menggunakan pendekatan cross sectional. Pengumpulan data dilakukan di bulan Desember 2017 pada 82 lansia dengan menggunakan cluster random sampling. Hasil analisis spearman rank menunjukkan bahwa tidak ada hubungan Antara pencapaian tugas perkembangan keluarga tahap VIII dengan perilaku pemenuhan kebutuhan spiritual : sholat pada lansia ( $p$ value $0,359>0,05$ ). Tugas perkembangan keluarga tercapai $(56,1 \%)$ dan rata-rata perilaku pemenuhan kebutuhan spiritual : sholat lansia adalah 69,11. Dukungan keluarga sangat penting bagi lansia, apalagi dalam melaksanakan tugas perkembangan keluarga dengan lansia. Namun, dari hasil penelitian didapatkan pencapaian tugas perkembangan keluarga hanya sedikit berpengaruh terhadap perilaku pemenuhan kebutuhan spiritual : sholat lansia, hal tersebut dapat dipengaruhi oleh faktor lain seperti lansia memiliki keyakinan dan kesadaran dalam menjalankan aktivitas keagaaman seperti sholat untuk bekal di akhirat.

Kata Kunci: aging family, sholat, lanjut usia 


\section{Pendahuluan}

Lansia merupakan tahap akhir perkembangan dan seringkali dipandang sebagai suatu masa degenerasi biologis yang disertai dengan berbagai keadaan yang menyertai proses menua. Ditinjau dari aspek kesehatan, dengan semakin bertambahnya usia maka lansia lebih rentan terhadap berbagai keluhan fisik, baik karena faktor alamiah maupun karena penyakit [1]. Selain itu, Lansia dalam menjalankan rutinitas keseharian mempunyai keterbatasan yang disebabkan oleh perubahan fisik serta psikologis yang berada pada perkiraan usia enam puluh tahun [2].

Menurut hasil studi pendahuluan yang dilakukan pada 16 Oktober 2017 di Lingkungan Tegal Boto Lor Kelurahan Sumbersari didapatkan hasil dari 10 orang lansia terdapat 6 orang lansia $(60 \%)$ tidak melaksanakan sholat dan 4 orang lansia (40\%) yang melaksanakan sholat dan melakukan berdzikir setelah sholat. Hal demikian menjadi alasan bahwa dalam melaksanakan rutinitas keseharian khususnya shalat, para lanjut usia membutuhkan peran keluarga dalam membimbing pelaksanannya.

Menurut penelitian dinyatakan bahwa terdapat hubungan yang bermakna antara dukungan keluarga pada lansia dengan tingkat kemandirian lansia dalam pemenuhan aktivitas sehari-hari [3]. Oleh karena itu, pengaruh lingkungan terutama keluarga sangat berperan penting terhadap pembentukan sikap ataupun perilaku lansia dalam melakukan aktivitas beribadah khususnya sholat [4].

Adanya dukungan keluarga akan memberikan kekuatan dan menciptakan suasana saling memiliki satu sama lain pada anggota keluarga tersebut dalam memenuhi kebutuhan perkembangan keluarga [5]. Salah satu kebutuhan yang harus dipenuhi lansia yaitu kebutuhan spiritual (sholat). Adanya dukungan keluarga pada lansia diharapkan dapat membentuk perilaku sholat yang baik pada lansia tersebut. Berdasarkan uraian diatas peneliti ingin menganalisis hubungan pencapaian tugas perkembangan keluarga dengan perilaku pemenuhan kebutuhan spiritual: sholat pada lansia di Kelurahan Sumbersari Kabupaten Jember.

\section{Metode Penelitian}

Metode penelitian ini menggunakan desain penelitian korelasi dengan rancangan penelitian cross sectional. Teknik pengambilan sampel menggunakan cluster random sampling dengan melibatkan 82 responden. Penelitian ini dilakukan di Kelurahan Sumbersari Kecamatan Sumbersari Kabupaten Jember. Waktu Penelitian dilakukan pada bulan April 2017 sampai dengan Desember 2017. Teknik pengumpulan data dalam penelitian ini menggunakan kuesioner pada responden. Analisis data menggunakan analisis univariat dan bivariat, analisis bivariat berupa uji parametrik yakni spearman rank dengan interval kepercayaan $95 \% \quad(\alpha=0.05)$. Etika penelitian pada penelitian ini adalah Informed consent, confidentialy, justice, dan benefeciency.

\section{Hasil Penelitian \\ Karakteristik Responden}

Tabel 1. Rerata Karakteristik Lansia Berdasarkan Usia $(n=82)$

\begin{tabular}{cccc}
\hline Variabel & Mean & Median & $\begin{array}{c}\text { Minimal- } \\
\text { Maksimal }\end{array}$ \\
\hline $\begin{array}{c}\text { Usia } \\
\text { (tahun) }\end{array}$ & 68,30 & 67,50 & $60-86$ \\
\hline
\end{tabular}

Sumber : Data Primer Desember 2017

Tabel 2. Distribusi karakteristik lansia berdasarkan jenis kelamin, pendidikan terakhir, dan pekerjaan $(n=82)$

\begin{tabular}{llcc}
\hline No. & $\begin{array}{c}\text { Karakteristik } \\
\text { Lansia }\end{array}$ & Frekuensi & $\begin{array}{c}\text { Persentase } \\
(\%)\end{array}$ \\
\hline $1 . \quad \begin{array}{l}\text { Jenis Kelamin } \\
\text { a. Laki-laki }\end{array}$ & 31 & 37,8 \\
b. Perempuan & 51 & 62,2 \\
\hline Total & 82 & 100 \\
\hline $2 . \quad$ Pendidikan & & \\
& Terakhir & & \\
& a. Tidak Sekolah & 23 & 28,1 \\
b. SD & 20 & 24,4 \\
& C. SMP & 16 & 19,5 \\
d. SMA & 12 & 14,6 \\
e. S1/D3 & 11 & 13,4 \\
\hline Total & 82 & 100 \\
\hline 3. Pekerjaan & & \\
& Sebelumnya & 19 & 23,2 \\
a. Tidak Bekerja & 19 & 13,4 \\
b. Buruh & 11 & 13,4 \\
c. Petani & 11 & 19,5 \\
d. Swasta & 16 & 15,9 \\
e. PNS & 13 & 14,6 \\
\hline f. Lainnya & 12 & 100 \\
\hline Total & 82 &
\end{tabular}

Sumber : Data Primer Desember 2017 


\begin{tabular}{|c|c|c|c|}
\hline $\begin{array}{l}\text { Pencapa } \\
\text { Tahap VI }\end{array}$ & $\begin{array}{l}\text { Tuan } P \\
\text { III (aging family }\end{array}$ & $\begin{array}{l}\text { erkembanga } \\
\text { Pada Lansi }\end{array}$ & Keluarga \\
\hline Tabel 3. & Distribusi & Pencapaian & Tuge \\
\hline & $\begin{array}{l}\text { Perkembangan } \\
(\mathrm{n}=82)\end{array}$ & Keluarga & Tahap \\
\hline $\begin{array}{l}\text { Pence } \\
\text { Perl } \\
\text { Keluar }\end{array}$ & $\begin{array}{l}\text { apaian Tugas } \\
\text { kembangan } \\
\text { rga Tahap VIII }\end{array}$ & Frekuensi & $\begin{array}{c}\text { Persentase } \\
\text { (\%) }\end{array}$ \\
\hline$T_{T}$ & apai & 4 & $\begin{array}{l}56,1 \\
439\end{array}$ \\
\hline b. Iidal & Tercapai & 0 & 43,9 \\
\hline Total & & 82 & 100 \\
\hline
\end{tabular}

Sumber : Data Primer Desember 2017

Tabel 4. Distribusi Indikator Pencapaian Tugas Perkembangan Keluarga Tahap VIII Lansia $(\mathrm{n}=82)$

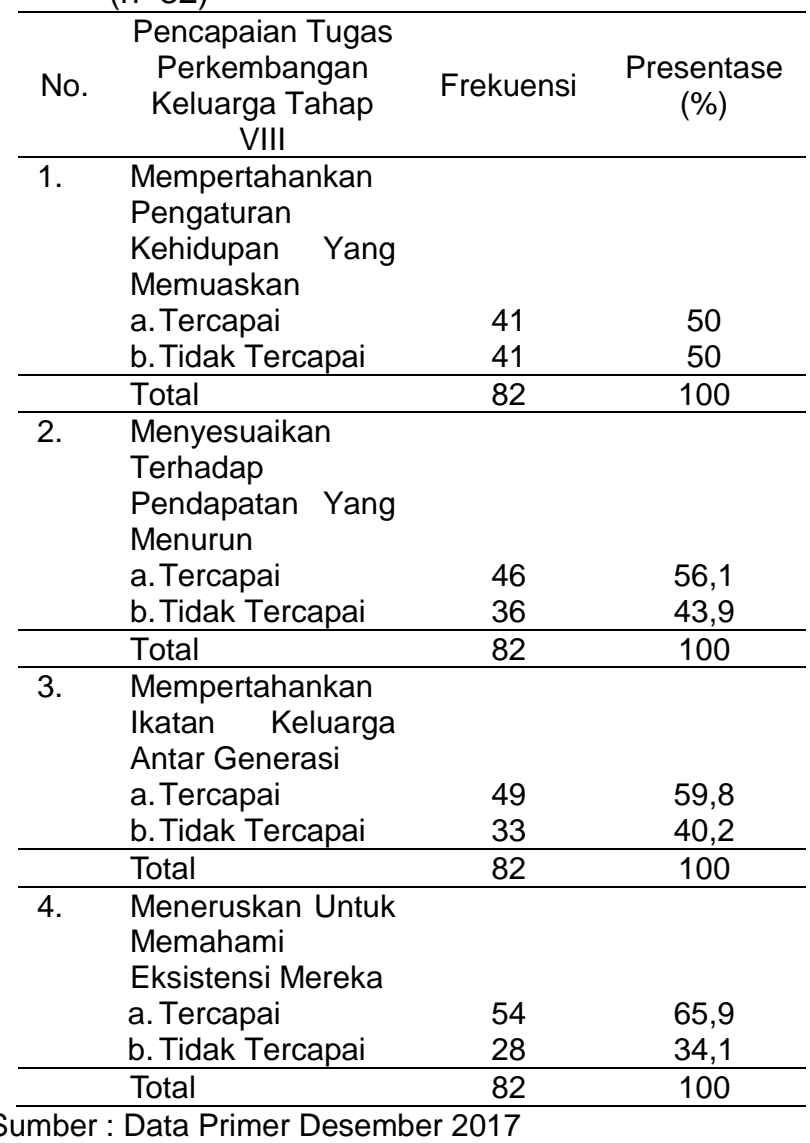

Perilaku Pemenuhan Kebutuhan Spiritual: Sholat Lansia

Tabel 5. Rerata Perilaku Pemenuhan Kebutuhan Spiritual: Sholat Lansia $(\mathrm{n}=82)$

\begin{tabular}{lccc}
\hline \multicolumn{1}{c}{ Variabel } & Mean & Median & $\begin{array}{c}\text { Minimal- } \\
\text { Maksimal }\end{array}$ \\
\hline $\begin{array}{l}\text { Perilaku Pemenuhan } \\
\text { Kebutuhan Spiritual : } \\
\text { Sholat }\end{array}$ & 69,11 & 73,00 & $15-75$ \\
\hline $\begin{array}{l}\text { Indikator } \\
\text { a. Waktu } \\
\quad \text { Pelaksanaan }\end{array}$ & 8,61 & 8 & $2-10$ \\
\hline $\begin{array}{l}\text { b. Ketepatan } \\
\text { Gerakan }\end{array}$ & 28,94 & 30 & $6-30$ \\
\hline c. Kekhusyukan & 31,56 & 35 & $7-35$ \\
\hline
\end{tabular}

Sumber : Data Primer Desember 2017

Hubungan Pencapaian Tugas Perkembangan

Keluarga Tahap VIII (aging family) dengan Perilaku Pemenuhan Kebutuhan Spiritual: Sholat Pada Lansia

Tabel 6. Hubungan Pencapaian Tugas Perkembangan Keluarga Tahap VIII dengan Perilaku Pemenuhan Kebutuhan Spiritual: Sholat Pada Lansia $(\mathrm{n}=82)$

\begin{tabular}{cll}
\hline & Pencapaian & Perilaku \\
& Tugas & Pemenuhan \\
Variabel & Perkembangan & Kebutuhan \\
& Keluarga & Spiritual : \\
& Tahap VIII & Sholat \\
\hline p value & & 0,359 \\
\hline $\mathbf{N}$ & & 82 \\
\hline
\end{tabular}

Sumber : Data Primer Desember 2017

Berdasarkan Tabel 6 dapat diambil kesimpulan bahwa tidak terdapat hubungan antara pencapaian tugas perkembangan keluarga tahap VIII (aging family) dengan perilaku pemenuhan kebutuhan spiritual : sholat $(p=0,359)$.

\section{Pembahasan \\ Karakteristik Responden}

Hasil penelitian menunjukkan bahwa rata-rata usia lansia adalah 68,30. Tahap perkembangan manusia dapat mempengaruhi status spiritual seseorang [6]. Pada kelompok usia pertengahan, lansia memiliki lebih banyak waktu untuk melakukan kegiatan keagamaan dan berusaha untuk mengerti nilai agama yang diyakini oleh generasi muda. Selain itu terdapat hubungan yang signifikan antara perkembangan spiritualitas dan tingkat usia [7].

Kategori jenis kelamin diketahui sebagian besar berjenis kelamin perempuan yaitu sebesar 52 orang $(62,2 \%)$. Hal ini 
dikarenakan responden perempuan lebih banyak dijumpai daripada responden laki-laki, sehingga kesempatan responden perempuan untuk dilakukan penelitian lebih banyak dibandingkan responden laki-laki. Kondisi lansia di Indonesia menunjukkan bahwa populasi lansia perempuan lebih tinggi dibandingkan lansia laki-laki. Hal ini menunjukkan Usia Harapan Hidup (UHH) perempuan lebih tinggi dibandingkan lansia laki-laki [8].

Hasil penelitian pada kategori tingkat pendidikan menunjukkan bahwa jumlah pendidikan terbanyak adalah tidak sekolah dengan jumlah 23 lansia (23,1\%). Hal ini sesuai dengan hasil Survei Sosial Ekonomi Nasional tahun 2014 yang memperlihatkan bahwa lansia 2014 memiliki pendidikan rendah. Sebanyak $21,03 \%$ lansia tidak dapat membaca dan menulis dan menurut tingkat pendidikannya, lebih dari setengah (56,85\%) penduduk lansia tidak memiliki ijazah pendidikan apapun. Sementara itu, yang memiliki ijazah $\mathrm{SD} /$ sederajat sebesar $25,68 \%$, sisanya sebesar $17,47 \%$ memiliki ijazah SMP/sederajat atau lebih. Angka rata-rata lama sekolah lansia juga mengindikasikan hal yang sama, rata-rata lama sekolah sebesar 4,27 tahun artinya bahwa secara rata-rata lansia putus sekolah di kelas 5 SD/sederajat [8].

Distribusi pekerjaan lansia dikategorikan menjadi tidak bekerja, buruh, petani, swasta, PNS dan lainnya. Sebagian besar lansia tidak bekerja sebanyak 19 orang (23,2\%). Sebagian besar yang bekerja adalah lansia laki-laki sedangkan lansia perempuan tidak bekerja karena suami (lansia laki-laki sudah bekerja untuk mencukupi kebutuhan sehari-hari. Hal ini sesuai dengan hasil Survei Sosial Ekonomi Nasional tahun 2014 proporsi lansia laki-laki yang bekerja $(63,81 \%)$ lebih besar daripada lansia perempuan (32,88\%) [8].

\section{Pencapaian Tugas Perkembangan Keluarga Tahap VIII (Aging Family)}

Hasil penelitian menunjukkan bahwa pencapaian tugas perkembangan keluarga tahap VIII di Kelurahan Sumbersari Kecamatan Sumbersari Kabupaten Jember bervariasi. Lebih dari 50\% keluarga dengan lansia melaksanakan tugas perkembangan keluarga tahap VIII. Menurut penelitian didapatkan hasil bahwa lebih dari tiga per empat keluarga responden laki-laki $(80,6 \%)$ dan hampir tiga per empat keluarga responden perempuan memiliki tingkat pemenuhan perkembangan tugas keluarga terkategori cukup [9].
Hasil penelitian menunjukkan bahwa distribusi pencapaian tugas perkembangan keluarga tahap VIII sebanyak 46 lansia $(56,1 \%)$ merasa tugas perkembangannya terpenuhi. Hal ini menunjukkan bahwa tugas perkembangan keluarga tahap VIII (aging Family) pada lansia tercapai. Tugas perkembangan keluarga yang tercapai diharapkan dapat membantu lansia dalam melaksanakan aktivitas sehari-hari, dimana usia lanjut mengalami penurunan kondisi fisik/biologis, kondisi psikologis, serta perubahan kondisi sosial.

Tugas perkembangan keluarga tahap VIII dikatakan tercapai apabila keluarga telah melaksanakan empat indikator tugas perkembangan keluarga tahap VIII yakni mempertahankan pengaturan kehidupan yang memuaskan, penyesuaian terhadap pendapatan yang menurun, mempertahankan ikatan keluarga antar generasi dan meneruskan untuk memahami eksistensi lansia.

Hasil penelitian menunjukkan bahwa pada indikator mempertahankan pengaturan kehidupan yang memuaskan terdapat 41 lansia $(50 \%)$ menunjukkan tugas perkembangan keluarga tahap VIII tercapai. Kepuasan dianggap sebagai memiliki perasaan menarik secara fisik dan mampu mengontrol hidupnya sendiri sehingga membuat seseorang mendapatkan kepuasan dalam hidupnya. Seseorang yang mengalami penurunan kemampuan seperti lansia, mengalami perubahan yang berhubungan dengan kepuasan hidupnya. Dukungan dan dorongan keluarga serta kerabat untuk membantu merawat lansia dapat memberikan kepuasan hidup bagi lansia [10].

Indikator penyesuaian terhadap pendapatan yang menurun didapatkan hasil bahwa sebanyak 46 lansia (56,1\%) menunjukkan tugas perkembangan keluarga tahap VIII tercapai. Dampak pensiun bagi lansia adalah menurunnya pendapatan. Sehingga lansia membutuhkan bantuan dari orang lain untuk memenuhi kebutuhannya [11]. Tanggung jawab untuk memberikan dan membiayai perawatan biasanya bertumpu pada keluarga [12]. Menurut Penelitian menunjukkan hasil bahwa tugas perkembangan keluarga mengenai penyesuaian terhadap pendapatan yang menurun tercapai. Oleh karena itu, lansia yang pensiun dan tidak bekerja dapat terpenuhi semua kebutuhannya [9].

Indikator mempertahankan ikatan keluarga antar generasi didapatkan hasil bahwa sebanyak 49 lansia $(59,8 \%)$ menunjukkan tugas 
perkembangan keluarga tahap VIII tercapai. Bentuk hubungan antar generasi umumnya terjadi dalam bentuk dukungan orangtua terhadap anaknya. Menurutnya orangtua akan senantiasa memberikan dukungan finansial dan kasih sayang untuk anaknya. Orang tua akan mendapat perhatian lebih dari anaknya ketika usianya sudah mencapai usia lanjut atau mengalami kecacatan. Melalui hal tersebut keluarga ingin lansia tetap menjalin komunikasi dengan kerabat terdekat sehingga silaturahim antara lansia dengan kerabat tetap terjaga [13].

Indikator meneruskan untuk memahami eksistensi lansia didapatkan hasil bahwa sebanyak 54 lansia $(65,9 \%)$ menunjukkan tugas perkembangan keluarga tahap VIII tercapai. Orang lanjut usia harus memahami keberadaan mereka. Hal penting dari aktivitas ini terletak pada fakta bahwa penelaahan kehidupan memudahkan penyesuaian terhadap situasisituasi yang sulit dan memberikan pandangan terhadap kejadian-kejadian masa lalu [12].

\section{Perilaku Pemenuhan Kebutuhan Spiritual: Sholat Lansia}

Hasil penelitian menunjukkan bahwa rerata nilai perilaku pemenuhan kebutuhan spiritual sholat pada lansia adalah 65,11 (total pencapaian $86,81 \%$ dari skor total $100 \%$ ). Masa tua adalah di mana kecenderungan menerima pendapat keagamaan sudah meningkat. Penerimaan pendapat keagamaan tersebut akan diikuti dengan perilaku beribadah kepada Allah Swt [14]. ibadah sholat dalam ajaran islam mempunyai kedudukan tertinggi diantara ibadah-ibadah lainnya [15]. Sholat adalah suatu kewajiban yang harus dilakukan oleh umat islam yang telah memenuhi syarat [16]. Dalam penelitian ini responden mayoritas melaksanakan ibadah sholat sesuai dengan perintah Allah Swt, dilihat dari jawabannya hampir seluruh responden melaksanakan ibadah sholat.

Mengenai esensi ibadah sholat, bukan hanya sekedar pelaksanaan sholatnya tetapi dilihat dari mulai prosesnya seperti dari mulai berwudhu sampai bagaimana pengaruh dari pelaksanaannnya. Instrumen sholat dalam penelitian ini meliputi tiga aspek yang terdiri dari waktu pelaksanaan sholat, ketepatan gerakan dan kekhusyukan [16].

Aspek waktu pelaksanaan sholat mengukur keteraturan lansia dalam melaksanakan sholat. Teratur dalam melaksanakan sholat maksudnya adalah setiap hari mengerjakan sholat lima waktu dan tidak ada satu pun yang ditinggalkan.
Hasil penelitian menunjukkan bahwa rerata nilai waktu pelaksanaan sholat lansia adalah 8,61 (total pencapaian $86,1 \%$ dari skor total $100 \%$ ). Menurut Penelitian didapatkan hasil bahwa hampir setengah responden lansia di UPT Pelayanan Sosial Lanjut Usia sholatnya tergolong teratur yaitu sebanyak 17 orang (49\%) [17]. Keteraturan sholat diharapkan mempunyai efek yang besar pada tiga faktor pendukung yang berupa faktor ketepatan dan disiplin, kesadaran dan tanggung jawab serta kekuatan kehendak dalam mengatasi pengaruh lingkungan. Orang-orang yang tinggi nilainya dalam ketiga faktor pendukung tersebut diharapkan akan lebih tinggi pula nilainya dalam segi keteraturan dalam sholat sehingga akan memperoleh manfaat yang besar dari sholatnya [18].

Aspek ketepatan gerakan sholat meliputi ketepatan gerakan wudhu dan ketepatan gerakan sholat. Penelitian pada aspek ini bertujuan untuk melihat kesempurnaan gerakan wudhu dan gerakan sholat yang dilakukan oleh lansia. Hasil penelitian menunjukkan bahwa rerata nilai ketepatan gerakan sholat pada lansia adalah 28,94 (total pencapaian $96,46 \%$ dari skor total $100 \%$ ). Jika mengerjakan wudhu dengan benar sesuai dengan tuntunan agama, maka manfaatnya akan dapat kita rasakan baik secara fisik maupun psikis [19]. Selain itu, berwudhu dapat menurunkan emosi dan menyeimbangkan hormon stress dalam tubuh [16].

Aspek kekhusyukan dalam penelitian ini meliputi kekhusyukan dalam niat, bacaan serta kekhusyukan dalam melakukan gerakan sholat. Hasil penelitian menunjukkan bahwa rerata nilai kekhusyukan adalah 31,56 (total pencapaian $90,17 \%$ dari skor total $100 \%$ ). Dalam niat terdapat keikhlasan dan sikap khusyuk. Meski secara singkat dan hanya satu kali dilakukan setiap sholat, tetapi kekhusyukan dan keikhlasan sholat tercermin dari niat seseorang. Disinilah makna penting dari niat, jika niatnya khusyuk maka khusyuk pula sholatnya [18]. Ketika sholat seseorang khusyuk, maka hatinya akan menjadi tenang. Hati yang tenang akan membawa seseorang pada kondisi mental dan fisik terbaik serta suasana hati yang baik dan emosi yang stabil [20].

\section{Hubungan Pencapaian Tugas Perkembangan Keluarga Tahap VIII (aging family) dengan Perilaku Pemenuhan Kebutuhan Spiritual: Sholat Pada Lansia}

Hasil uji statistik pada penelitian ini menunjukkan bahwa hipotesis ditolak dimana 
nilai $p$-value $=0,359$ yang artinya tidak ada hubungan antara pencapaian tugas perkembangan keluarga tahap VIII (aging Family) dengan perilaku pemenuhan kebutuhan spiritual : sholat pada lansia di kelurahan sumbersari kecamatan sumbersari kabupaten jember. Hasil ini tidak sesuai dengan hasil penelitian lain dimana terdapat hubungan yang signifikan antara peran keluarga dalam pemenuhan kebutuhan spiritual dengan tingkatan spiritualitas pada lansia di Desa Beji $(p=0,036)[21]$.

Menurut peneliti, tidak adanya hubungan antara pencapaian tugas perkembangan keluarga tahap VIII (aging Family) dengan perilaku pemenuhan kebutuhan spiritual : sholat dikarenakan ada faktor lain yang mempengaruhi perilaku pemenuhan spiritual : sholat pada lansia. Faktor perilaku sendiri ditentukan oleh tiga faktor utama yaitu faktor predisposisi (predisposing factor), faktor pemungkin (enabling factor), faktor penguat (reinforcing factor). Faktor predisposisi yang paling berperan mempengaruhi perilaku lansia dalam melaksanakan pemenuhan kebutuhan spiritual : sholat [22].

Usia lanjut adalah orang yang sudah memiliki kesadaran dalam menjalankan ibadah [23]. Munculnya kesadaran beragama pada umumnya didorong oleh adanya keyakinan keagamaan yang merupakan keadaan yang ada pada diri seseorang. Adanya kesadaran itulah akhirnya terbentuk tingkah laku keagamaan pada seseorang. Kesadaran akan norma-norma agama berarti individu menghayati, menginternalisasi dan mengintegrasikan norma tersebut kedalam diri pribadinya sehingga akan menjadi bagian dari hati dan kepribadiannya [24].

Namun, pada usia lanjut tidak semua aktivitas keagamaan dapat dilaksanakan dengan baik, sehingga ada keterbatasan yang disebabkan kondisi fisik yang tidak kuat lagi [23]. Sehingga idealnya lansia membutuhkan keluarga dalam pemenuhan tugas perkembangan. Mempertahankan kehidupan yang memuaskan adalah tugas keluarga lansia yang paling penting [12]. Apabila keluarga tidak menjalankan tugas perkembangan dengan baik, maka manusia usia lanjut tidak memelihara dan mempertahankan harga dirinya dan akan merasa tegang, takut, murung, sedih, kecewa, marah, putus asa dan sebagainya [23].

Dukungan keluarga sangat penting bagi lansia, apalagi dalam melaksanakan tugas perkembangan keluarga dengan lansia.
Namun, dari hasil penelitian didapatkan pencapaian tugas perkembangan keluarga tidak berhubungan dengan perilaku pemenuhan kebutuhan spiritual : sholat lansia, hal tersebut dapat dipengaruhi oleh faktor lain. Menurut peneliti, hal ini disebabkan karena lansia memiliki keyakinan dan kesadaran dalam menjalankan aktivitas keagaaman seperti sholat untuk bekal di akhirat. Sehingga lansia dalam menjalankan ibadah sholat dapat melaksanakan sendiri tanpa bantuan ataupun perintah dari keluarga. Semakin lanjut usia seseorang, maka semakin sering pula mereka memikirkan tentang kematian. Hal ini dipicu oleh kondisi mental dan fisik yang semakin menurun. Kekhawatiran ini biasanya terkait dengan peningkatan rasa keagamaan, cenderung lebih taat beribadah, dan melakukan aktivitas-aktivitas sosial bermanfaat. Selain itu, minat beragama secara umum ditentukan dari usia-usia sebelumnya, meskipun kadang-kadang terjadi perubahan sikap beragama yang drastis pada diri seseorang [23]. Oleh karena itu, perawat diharapkan dapat membantu keluarga untuk membentuk karakter beragama sejak dini sehingga di masa tua nanti perilaku beragama semakin baik.

\section{Simpulan dan Saran Simpulan}

Berdasarkan hasil penelitian dan pembahasan mengenai hubungan pencapaian tugas perkembangan keluarga tahap VIII (aging family) dengan perilaku pemenuhan kebutuhan spiritual: sholat lansia di Kelurahan Sumbersari Kecamatan Sumbersari Kabupaten Jember dapat disimpulkan bahwa tidak ada hubungan signifikan antara pencapaian tugas perkembangan keluarga tahap VIII (aging family) dengan perilaku pemenuhan kebutuhan spiritual: sholat lansia di Kelurahan Sumbersari Kecamatan Sumbersari Kabupaten Jember.

\section{Saran}

Berdasarkan hasil penelitian ini, diharapkan perawat dapat memfasilitasi lansia untuk menjaga kesehatan fisik maupun psikis lansia sehingga lansia dalam menjalankan aktivitas khususnya sholat dapat dilakukan dengan teratur dan baik. 


\section{Daftar Pustaka}

[1] Kementerian Kesehatan RI. Situasi dan analisis usia lanjut. Jakarta: Pusat Data dan Informasi; 2014.

[2] Ummah A. Hubungan kebutuhan spiritual dengan kualitas hidup pada lansia di panti wredha kota semarang. Skripsi. Semarang: Jurusan Keperawatan, Fakultas Kedokteran, Universitas Diponegoro; 2016.

[3] Ratnasari N \& Nurtanti S. Hubungan dukungan keluarga dengan kemandirian lansia dalam pemenuhan aktivitas seharihari di wilayah kerja puskesmas selogiri, kabupaten wonogiri. Wonogiri: Akademi Keperawatan Giri Satria Husada; 2007.

[4] Tasbih A. Makna shalat berjamaah pada lansia. Skripsi. Yogyakarta: Program Studi Psikologi, Fakultas IImu Sosial Dan Humaniora, Universitas Islam Negeri Sunan Kalijaga; 2012.

[5] Wulandhani dkk. Hubungan dukungan keluarga dengan motivasi lansia hipertensi dalam memeriksakan tekanan darahnya. JOM PSIK Vol. 1 No.2. Riau: Program Studi IImu Keperawatan, Universitas Riau; 2014.

[6] Hamid AY. Aspek spiritual dalam keperawatan. Jakarta: Widya Medika; 2008.

[7] Jalaluddin. Tingkat usia dan perkembangan spiritualitas serta faktor yang melatar belakanginya di majelis tamasya rohani riyadhul jannah palembang. Jurnal Intizar. 2015; 21(3).

[8] Hasil Survei Sosial Ekonomi Nasional. Statistik penduduk lanjut usia 2014. Jakarta: BPS; 2014.

[9] Dwiputri RM. Pemenuhan perkembangan tugas keluarga serta kepuasan pernikahan pada lansia laki-laki dan perempuan. Skripsi. Bogor: Departemen IImu Keluarga Dan Konsumen, Fakultas Ekologi Manusia, Institut Pertanian Bogor; 2014.

[10] Ostwald SK. 2008. Predictors of life satisfaction among stroke survivors and spousal caregivers: a narrative review. [internet]. 2008. [diambil tanggal 18 Januari 2018] diakses dari https://nursing.uth.edu/coa/downloads/care s/Life\%20Satisfaction\%20Narrative\%20Rev iew.pdf.

[11] Noorkasiana, Tamher. Kesehatan usia lanjut dengan pendekatan asuhan keperawatan. Jakarta: Salemba Medika; 2009.

[12] Ramadhan F. Gambaran pemenuhan tugas perkembangan keluarga pada lansia dengan stroke di rumah sakit umum daerah dr. zainoel abidin banda aceh. Skripsi. Banda Aceh: Universitas Syiah Kuala; 2014.

[13] Somantri J. Analisis karakteristik lanjut usia dengan hubungan antar generasi di Desa Cihideung Ilir Kabupaten Bogor. Skripsi. Bogor: Departemen Sains Komunikasi Dan Pengembangan Masyarakat, Fakultas Ekologi Manusia, Institut Pertanian Bogor; 2013.

[14] Hasan I. Studi religiusitas lansia terhadap perilaku keagamaan pada lansia perumahan tegal sari ledug kembaran banyumas. Islamadina. 2015; XV(2): 1-16.

[15] Permasandi HK. Peranan pembimbing agama dalam meningkatkan ibadah shalat pada lansia di balai perlindungan sosial dinas sosial provinsi banten. Skripsi. Jakarta: Fakultas ilmu Dakwah Dan IImu Komunikasi, Universitas Islam Negeri Syarif Hidayatullah; 2011.

[16] Suparman D. Pembelajaran ibadah shalat dalam perpekstif psikis dan medis. Jurnal. 2015; 9(2): 1979-8911.

[17] Uliyah M \& Faradimah. Keteraturan sholat lima waktu dengan tingkat depresi pada lansia. The Sun Vol. 2(1). Surabaya : Fakultas ilmu Kesehatan, Universitas Muhammadiyah Surabaya; 2015.

[18] Cahyani H.F. Hubungan shalat terhadap tekanan darah pada pasien hipertensi di Posbindu Anggrek Kelurahan Cempaka Putih Kecamatan Ciputat Timur. Skripsi. Jakarta : Program Studi IImu Keperawatan, Fakultas Kedokteran Dan IImu Kesehatan, Universitas Islam Negeri Syarif Hidayatullah, Jakarta; 2014.

[19] Sanusi M. Bedah lengkap kedashyatan sholat bagi kesehatan manusia. Yogyakarta: DIVA Press; 2010.

[20] Elzaky JM. Mukjizat kesehatan ibadah. Jakarta: syuruq; 2010.

[21] Widayanti A. Hubungan peran keluarga dalam pemenuhan kebutuhan spiritual dengan tingkatan spiritualitas pada lansia di desa beji wilayah kerja puskesmas leyangan ungaran timur. Artikel. Ungaran: Program Studi IImu Keperawatan, Sekolah Tinggi Ilmu Kesehatan Ngudi Waluyo; 2016.

[22] Notoatmodjo. Metodologi penelitian kesehatan. Jakarta : Rineka Cipta; 2010.

[23] Replita. Kondisi keberagamaan pada manusia usia lanjut (sebuah pendidikan 
Kharisma, et al, Hubungan Pencapaian Tugas Perkembangan Keluarga Tahap VIII ...

dan pembelajaran pada generasi muda).

Hikmah. 2015; 8(2): 63-74.

[24] Sitorus M. Psikologi agama. Medan:

Perdana Publshing; 2011. 